\title{
Three-dimensional numerical simulation of storm surge disaster
}

\author{
Cheng Wang ${ }^{1, \text { a }}$, XiaoLing Wang ${ }^{2, \mathrm{~b}}$, ZhengYin Zhou ${ }^{3, \mathrm{c}^{*}}$, \\ XueFei $\mathrm{Ao}^{4, \mathrm{~d}}$, MengQi Zhao ${ }^{5, \mathrm{e}}$ \\ 1,2,3,4,5 State Key Laboratory of Hydraulic Engineering Simulation and Safety, Tianjin University, \\ Tianjin, 300072, China \\ a2010301580287@whu.edu.cn, bwangx|@tju.edu.cn, 'chouzhengyin@126.com,

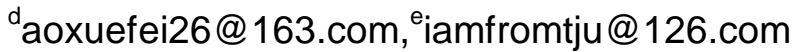

Keywords: Computational fluid dynamics; Storm surge flood; Three-dimensional k- $\varepsilon$ turbulence mathematical model; VOF method.

Abstract. The numerical simulation of storm surge flood routing is of great importance to the storm surge disaster management. Few studies devoted to the three-dimensional numerical stimulation of storm surge flood. At present, the three-dimensional $k$ - $\varepsilon$ turbulence mathematical model coupled with the VOF method was adopted to achieve this target. A simulation on a storm surge flood in a certain coastal area was performed, and the hydrology information was analyzed, which can provide a scientific basis for the storm surge disaster management.

\section{Introduction}

Storm surge disaster brings great threaten to the society, economy and safety of people in the coastal areas yearly. Therefore, conducting the research of the numerical simulation of storm surge flood routing has been concerned by the storm surge disaster managers.

The numerical stimulation method has been adopted by many researchers to study the storm surge flood routing in the coastal areas at present. ${ }^{1-5}$ However, the study of storm surge disaster mainly focuses on the two-dimensional numerical simulation which simplifies the actual three-dimensional flow and cannot reflect the vertical movement of the flow veritably.

The three-dimensional $k-\varepsilon$ turbulence mathematical model coupled with the volume of fluid (VOF) method was adopted in this paper to conduct the simulation of storm surge disaster. A simulation on a storm surge flood in a certain coastal area was performed, and the hydrology information, including the flood routing process, the flow rate and the water depth, was analyzed which can be useful to the consequence analysis, the flood control decision and the disaster response of the storm surge disaster.

\section{Three-dimensional k- $\varepsilon$ turbulence mathematical model}

The three-dimensional k- $\varepsilon$ turbulence mathematical model coupled with the VOF method, which can describe the free surface flow well and has been validated, 6 was adopted to conduct the numerical simulation of storm surge flood routing. The governing equations of the model, including the continuity equation, the momentum equation, the turbulent kinetic energy equation and the turbulence dissipation rate equation, are shown as follows, respectively:

$$
\begin{aligned}
& \frac{\partial \rho}{\partial t}+\frac{\partial\left(\rho u_{i}\right)}{\partial x_{i}}=0 . \\
& \frac{\partial\left(\rho u_{i}\right)}{\partial t}+\frac{\partial}{\partial x_{i}}\left(\rho u_{i} u_{j}\right)=-\frac{\partial P}{\partial x_{i}}+\frac{\partial}{\partial x_{j}}\left[\left(\mu+\mu_{t}\right)\left(\frac{\partial u_{i}}{\partial x_{j}}+\frac{\partial u_{j}}{\partial x_{i}}\right)\right] . \\
& \frac{\partial}{\partial t}(\rho k)+\frac{\partial}{\partial x_{j}}\left(\rho u_{i} k\right)=\frac{\partial}{\partial x_{i}}\left[\left(\mu+\frac{\mu_{t}}{\sigma_{k}}\right) \frac{\partial k}{\partial x_{j}}\right]+G-\rho \varepsilon .
\end{aligned}
$$




$$
\frac{\partial}{\partial t}(\rho \varepsilon)+\frac{\partial}{\partial x_{j}}\left(\rho u_{i} \varepsilon\right)=\frac{\partial}{\partial x_{i}}\left[\left(\mu+\frac{\mu_{t}}{\sigma_{\varepsilon}}\right) \frac{\partial \varepsilon}{\partial x_{i}}\right]+\frac{C_{1 \varepsilon} \varepsilon}{k} G-C_{2 \varepsilon} \rho \frac{\varepsilon^{2}}{k} .
$$

Where $\rho$ is density of fluid, $\mathrm{kg} / \mathrm{m}^{3} ; x_{i}$ is Cartesian coordinate, $\mathrm{m} ; u_{i}$ is absolute fluid velocity component, $\mathrm{m} / \mathrm{s} ; \mu_{j}$ is absolute fluid velocity component, $\mathrm{N} \cdot \mathrm{s} / \mathrm{m}^{2} ; P$ is piezometric pressure, $\mathrm{Pa} ; \mu$ is molecular dynamic viscosity, $\mathrm{N} \cdot \mathrm{s} / \mathrm{m}^{2} ; \mu_{t}$ is turbulent viscosity, $\mathrm{N} \cdot \mathrm{s} / \mathrm{m}^{2} ; k$ is turbulence kinetic energy, $\mathrm{m}^{2} / \mathrm{s}^{2} ; \varepsilon$ is dissipate of turbulence kinetic energy, $\mathrm{m}^{2} / \mathrm{s}^{2} ; G$ is turbulent energy ratio; $\sigma_{k}, \sigma_{\varepsilon}, C_{l \varepsilon}, C_{2 \varepsilon}$ are constants.

\section{Case study and results}

A storm surge flood of 50 year frequency in a certain coastal area was chosen as the object of study. The study area can be determined based on factors of terrain, water-retaining structures, rivers and so on, which is shown in Figure 1.

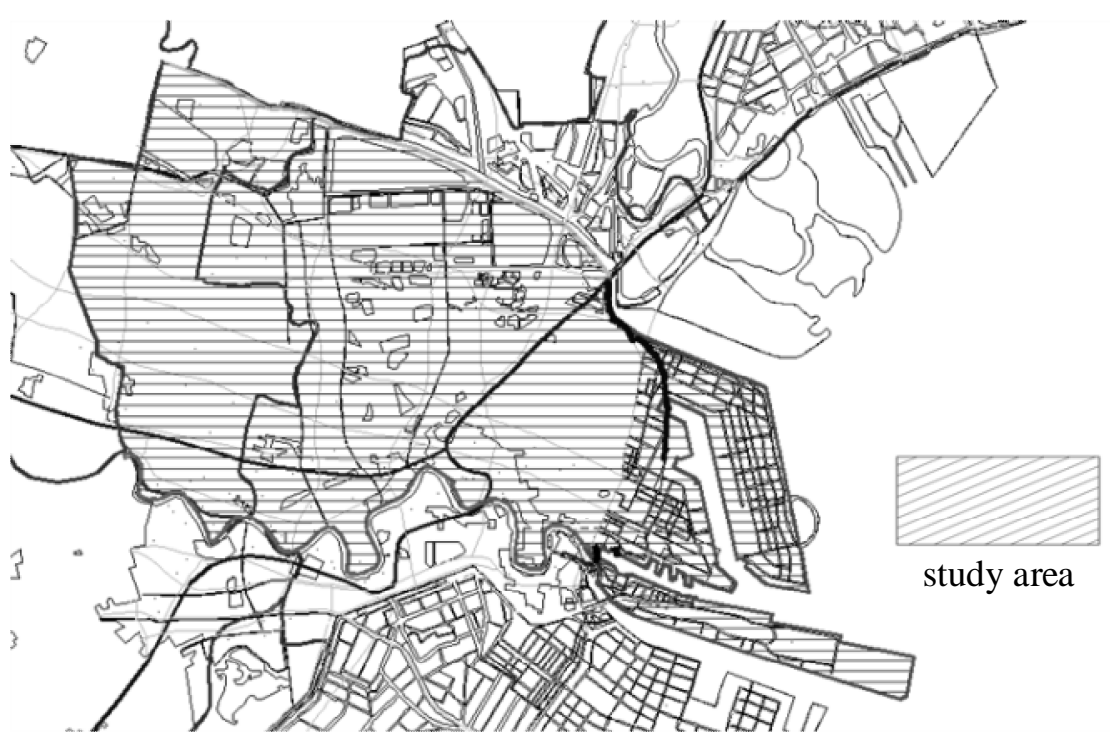

Fig. 1. The sketch map of the study area.

Dynamic distribution of the volume of fluid in the study area, which can describe the whole flood routing process, is shown in Figure 2. At the end of the flood routing, affected by the terrain, several dead water regions can be found.

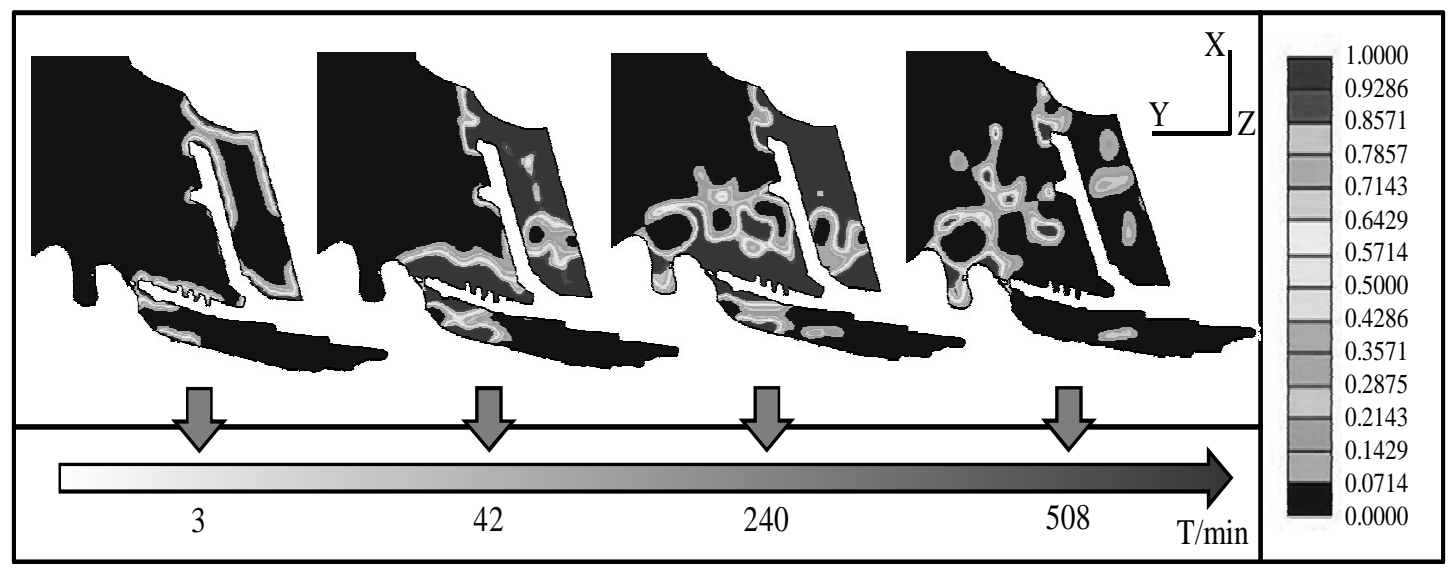

Fig. 2. Dynamic distribution of the volume of fluid (VOF) in the study area (dimensionless). 
The velocity distribution at 240min is shown in Figure 3. Because of the resistance of upland and seawall, the phenomena, such as the swirling flow and the backflow, appeared in these areas.

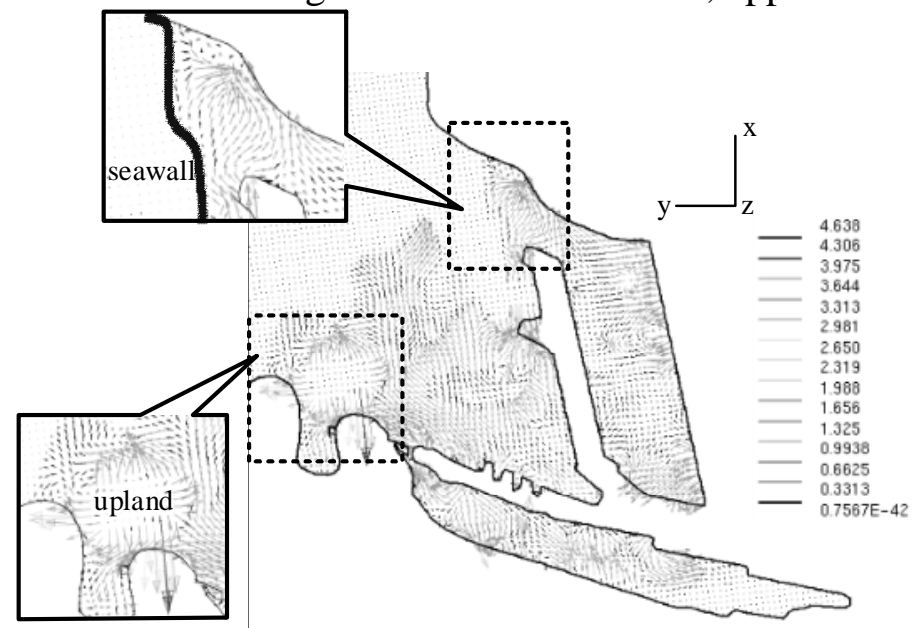

Fig. 3. The velocity analysis at $240 \mathrm{~min}$.

Four typical sites were selected here to analyze the water depths, shown in Figure 4(a). Affected by the locations and terrain, the water depth curves present different trends, shown in Figure 4(b). And the typical site 3 and typical site 4 existed the stagnant water, which was in accordance with the VOF analysis.

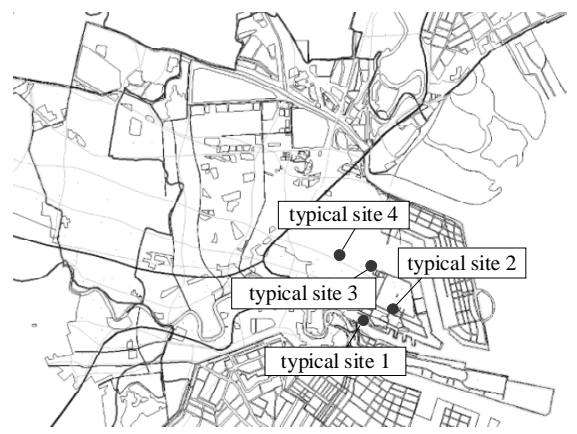

(a) The distribution of typical site

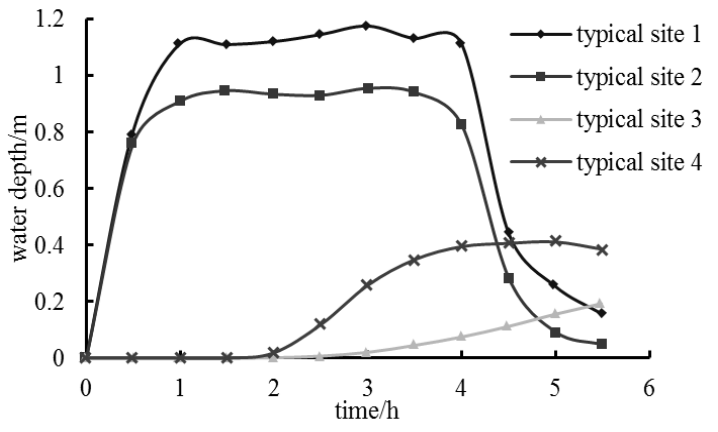

(b) The water depths of typical sites

Fig. 4. The water depths analysis of typical sites.

\section{Conclusion}

According to the research status that the analysis of storm surge disaster mainly focuses on the two-dimensional numerical simulation, the three-dimensional $\mathrm{k}-\varepsilon$ turbulence mathematical model coupled with the VOF method was adopted in this paper. A storm surge flood in a certain coastal area was simulated, and the hydrology which includes the flood routing process, the flow rate and the water depth, information was analyzed.

The results show that the three-dimensional numerical simulation can describe the whole flood routing process well, and find the phenomena, such as stagnant water, the swirling flow and the backflow, which can provide a scientific basis for the storm surge disaster management.

\section{Acknowledgments}

The research was supported by Foundation for Innovative Research Groups of the National Natural Science Foundation of China (Grant no. 51321065), the National Basic Research Program of China 
(973 Program) (Grant no. 2013CB035906) and the Natural Science Fund of Tianjin City (Grant no. 13JCYBJC19500).

\section{References}

[1] J. Benavente, L. Rio, F. J. Gracia, and J. A. Martinez-del-Pozo, Coastal flooding hazard related to storms and coastal evolution in Valdelagrana spit (Cadiz Bay Natural Park, SW Spain), Cont. Shelf. Res. 26, 9 (2006).

[2] R. Canizares, and J. L. Irish, Simulation of storm-induced barrier island morphodynamics and flooding, Coast. Eng. 55, 12 (2008).

[3] H. Z. Xu, K. Q. Zhang, J. A. Shen, and Y. P. Li, Storm surge simulation along the U.S. East and Gulf Coasts using a multi-scale numerical model approach, Ocean. Dynam. 60, 6 (2010).

[4] Y. P. Sheng, Y. F. Zhang, and V. A. Paramygin, Simulation of storm surge, wave, and coastal inundation in the Northeastern Gulf of Mexico region during Hurricane Ivan in 2004, Ocean. Model. 35, 4 (2010).

[5]A. D. Rao, P. L. N. Murty, I. Jain, R. S. Kankara S. K. Dube and T. S. Murty, Simulation of water levels and extent of coastal inundation due to a cyclonic storm along the east coast of India, Nat. Hazards. 66, 3 (2013).

[6] Z. Y. Zhou, X. L. Wang, R. R. Sun, X. F. Ao, X. P. Sun and M. R. Song, Study of the comprehensive risk analysis of dam-break flooding based on the numerical simulation of flood routing. Part II: Model application and results, Nat. Hazards. 72 (2014). 